The Perceived Role of Personal Social IdENTITy in the Promotion of ARTHRitis SELF-MANAGEMENT Programs

A Thesis presented to the Faculty of the Graduate School

at the University of Missouri - Columbia

In Partial Fulfillment

of the Requirements for the Degree

Master of Arts

by
ERIN WILLIS

Dr. Cynthia Frisby, Thesis Supervisor

August 2008 
The undersigned, appointed by the Dean of the Graduate School, have examined the thesis entitled

\section{THE PERCEIVED ROLE OF PERSONAL SOCIAL IDENTITY IN THE PROMOTION OF ARTHRITIS SELF-MANAGEMENT PROGRAMS}

presented by Erin Willis

a candidate for the degree of Master of Arts and hereby certify that, in their opinion, it is worthy of acceptance.

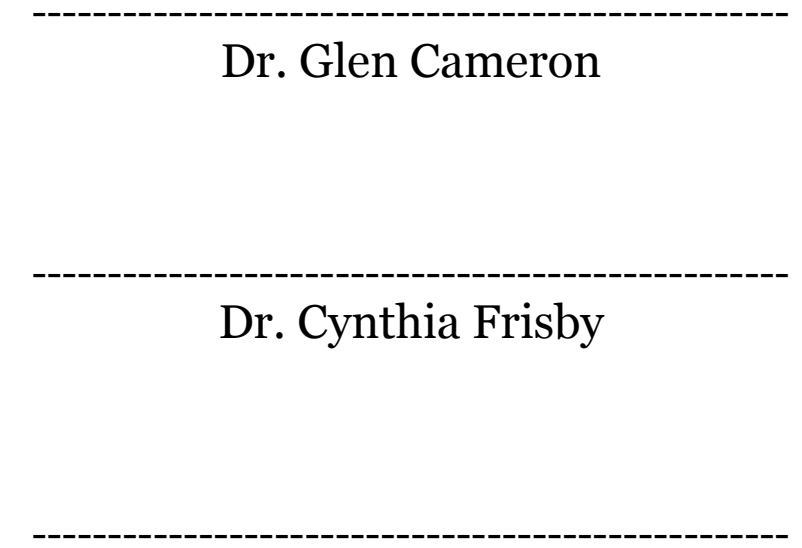

Dr. Jerry C. Parker

Dr. Yong Volz 


\section{ACKNOWLEDGEMENTS}

\section{The journey is the reward. - Chinese proverb}

While holding a graduate assistantship at the Missouri Arthritis Rehabilitation Research and Training Center (MARRTC), I was given the opportunity to explore the world of research. After attending the American College of Rheumatology (ACR) Conference in Boston in November 2007, I was turned onto a whole new world. Behind the scenes where no consumer even can begin to fathom - researchers are working on numerous projects to better the quality of life for people living with arthritis, and other rheumatic diseases. Since I have rheumatoid arthritis... I was moved. I cannot put into words the change that occurred in me. But, thankfully a change occurred.

I would like to acknowledge MARRTC, specifically Rebecca Woelfel, for giving me such an opportunity and for pushing me to be a better version of me. In addition, Drs. Glen Cameron and Jerry C. Parker have helped fuel my fire. I feel very lucky to have been given the opportunity to be part of such a dynamic team.

Dr. Yong Volz has taught me countless lessons and has been a close guide along the way. I am so appreciative of her attention. Yong has taken an interest in me, as a student, and her advice is simply priceless.

Finally, I acknowledge Dr. Cynthia Fribsy's dedication to this project. She has given criticism where needed most, but is also first to applaud my progress. She is a great inspiration.

I admire you all. 


\section{TABLE OF CONTENTS}

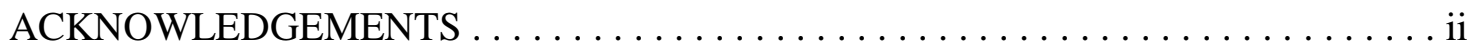

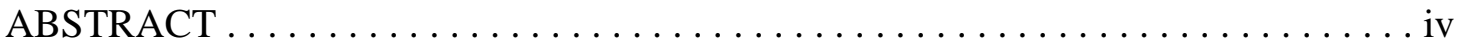

Chapter

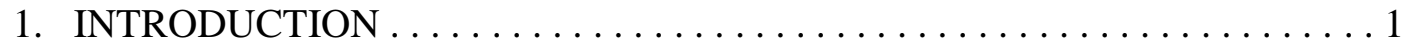

Goals of the Study

2. SOCIAL ROLE IDENTITY $\ldots \ldots \ldots \ldots \ldots \ldots \ldots \ldots \ldots \ldots \ldots \ldots \ldots \ldots \ldots \ldots \ldots$

3. ARTHRITIS SELF-MANAGEMENT PROGRAMS $\ldots \ldots \ldots \ldots \ldots \ldots \ldots 8$

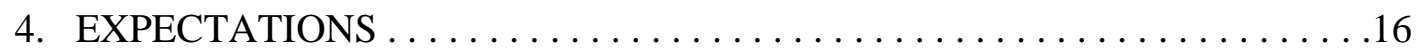

5. HEALTH COMMUNICATION . . . . . . . . . . . . . . . . . . . 18

6. METHODOLOGY . . . . . . . . . . . . . . . . . . . . . .

In-Depth Interviews

Ethnography

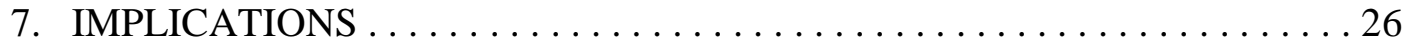

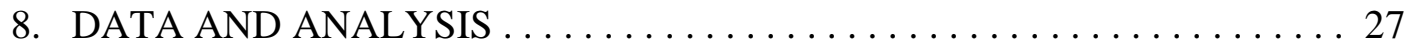

Social Roles and Realization of Identity

Utilization of Arthritis Self-Management Programs

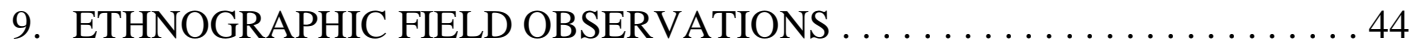
Asking for Help

Personal Narratives

Independence

10. CONCLUSION . . . . . . . . . . . . . . . . . . . . . . . 47

Appendix

I. INTERVIEW PARTICIPANT SURVEY $\ldots \ldots \ldots \ldots \ldots \ldots \ldots 5$

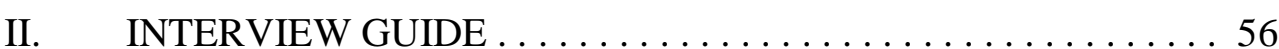

III. PARTICIPANT DEMOGRAPHICS $\ldots \ldots \ldots \ldots \ldots \ldots \ldots \ldots$

BIBLIOGRAPHY . . . . . . . . . . . . . . . . . . . . . . . . 59 


\title{
THE PERCEIVED ROLE OF PERSONAL SOCIAL IDENTITY IN THE PROMOTION OF ARTHRITIS SELF-MANAGEMENT PROGRAMS
}

\author{
Erin Willis
}

\author{
Dr. Cynthia Frisby, Thesis Supervisor
}

\begin{abstract}
This research attempts to understand how a person with arthritis perceives his or her own social role identity and how that might relate to the underutilization of arthritis self-management programs. The ultimate goal of this research is to learn how people with arthritis perceive themselves and their disease within a particular social role and how those perceptions shape healthrelated beliefs and behaviors.

Qualitative research methods provide a framework for this study, including in-depth interviews and ethnographic fieldwork. Data was collected and analyzed for themes and patterns, including social role identity and utilization of self-management strategies.

Arthritis self-management programs are designed for many purposes, including reducing pain and increasing mobility. However, many people with arthritis already practice arthritis self-management strategies although not aware of the implications. The promotion of such programs should communicate to people with arthritis the ability to fulfill social roles longer and with less effort by practicing formal self-management strategies.
\end{abstract}




\section{CHAPTER 1: INTRODUCTION}

This research attempts to understand how a person with arthritis perceives his or her own social role identity and how that might relate to the underutilization of arthritis self-management programs. The ultimate goal of this research is to learn how people with arthritis perceive themselves and their disease within a particular social role and how those perceptions shape healthrelated beliefs and behaviors.

This paper is based on findings drawn from research undertaken within a qualitative framework of analysis. In-depth qualitative interviews with people who have arthritis are not designed to produce statistically significant, or generalizable, findings. Rather, the aim is to bring to the attention of the reader certain aspects of the phenomena under study, and to develop an understanding of the phenomena in some depth (Agar, 1980). Gerhardt (1990) notes that in the area of long-term illnesses, it becomes vital for those involved in care and treatment to know what effects interventions have, not only in clinical terms, but also in terms of an individual's quality of life. Only then does it become possible for treatment and advice to be adapted to the everyday realities of people with arthritis.

Arthritis is the leading cause of disability in the United States, affecting one in five (or 46 million) adults. According to the Arthritis Foundation, arthritis is a term used to define over 100 diseases and rheumatic conditions and is projected to affect an estimated 67 million adults by 2030. 
Each year, arthritis costs the economy more than $\$ 128$ billion. It is estimated that people aged 6o years and older have, on average, 2.2 chronic conditions. Chronic disease is responsible for almost 70 percent of all health care expenditures (Lorig, et. al., 1999).

Research has shown those who participate in self-management programs can reduce pain by 20 percent and hospital visits by 40 percent. Arthritis selfmanagement programs are health promotion programs designed to educate people with arthritis on how to better understand their disease, cope with chronic pain, and to take an active role in managing their arthritis. Untreated or inadequately managed arthritis can have a negative impact on people with the disease by limiting physical function, quality of life, work, and the ability to manage other chronic conditions successfully (Theis, Helmick, Hootman, 2007).

However, even though effective self-management programs are available, only 11 percent of people with arthritis (18 years of age or older) have ever taken an educational course or class to teach them how to manage problems related to arthritis or joint symptoms (Centers for Disease Control and Prevention, NHIS, 2003).

The availability of arthritis self-management programs varies by state. The Arthritis Foundation's Arthritis Self-Management Program, was developed in the early 1980 s at Stanford University, Palo Alto, California, and each year only reaches from 8,000 to 12,000 adults who have been diagnosed as having a form of chronic arthritis (Kruger et. al., 1998). This is not to say that people with arthritis are not already practicing self-management strategies learned throughout the course of the disease. 
The prevalence of arthritis by state ranges from 17.9 percent to 37.2 percent, with the median being 27 percent (Centers for Disease Control and Prevention, 2000). My research took place only in Missouri, which has a slightly higher than average percentage of people with arthritis.

This research looks into personal accounts of people with arthritis, using a combination of in-depth interviews and ethnography. Often, patients' 'subjective' experiences are seen neither as valid, nor as being valuable research resources. However, this research explores patients' perspectives of their disease and how those thoughts influence health-related beliefs and behaviors. Physician and health care professional knowledge must acknowledge, value and focus on personal experience which will facilitate an understanding of human response to illness (Watson, 1985). 


\section{CHAPTER 2: SOCIAL ROLE IDENTITY}

Arthritis does not discriminate in persons affected by the degenerative disease. Despite recent treatment advances, arthritis remains one of the leading causes of disability. Its cardinal symptoms - pain, swelling, and stiffness in joints - often result in difficulty carrying out the simplest tasks in daily living. "Joint pain and immobility result in reduced involvement in familial, work, and social roles and lowered quality-of-life” (Revenson \& Felton, 1989, 344).

Much research has emphasized the importance of viewing the patient as a whole person with emotional as well as physical needs (Munhall, 1981; Oiler, 1982; Gortner, 1990). Morse (1991) writes that qualitative research is being identified as the major research approach for the exploration of feelings, spirits, attributes, values, meanings and characteristics of individuals or groups.

According to the Centers for Disease Control and Prevention, a recent survey (2003-2005 National Health Interview Survey) yielded the following results regarding the prevalence of doctor-diagnosed arthritis:

- Women (25.4\%); Men (17.6\%)

- Persons 65 years or older (50\%); 45-64 years old (29.3\%); 18-44 years old (7.9\%)

- Non-hispanic whites (24.3\%); Non-hispanic blacks (19.2\%); Hispanics (11.4\%)

Although rheumatic diseases do not pose any immediate life threats, they create a complex set of illness-related factors, including severe and often unpredictable pain, joint swelling and stiffness, physical disability, and uncertainty about disease progression. Because of these illness-related factors, chronic diseases present a number of threats to the self concept, which can 
adversely affect psychological well-being (Abraido-Lanza \& Revenson, 2006, 224). Social identity theory and research on illness intrusions are useful in understanding how chronic illness may have these effects.

Social identity theory proposes that social roles, such as being a parent, worker, or spouse, form the basis for identity (Thoits, 1991). Arthritis, however, often impacts the ability to perform various activities, including those required for the fulfillment of various social roles. The term "illness intrusions" refers to these disease-caused lifestyle disruptions that "interfere with continued involvements in valued activities and interests" (Devins, 1989, 112).

When Revenson and Felton (1989) asked respondents to describe the major problems they encountered in having a chronic illness, most often reported were a restricted lifestyle (82.2\%), limited movement (51.2\%), and pain (31.1\%). Illness intrusions may result directly from disability and pain, other features of illness that limit or impair functioning, or the need to limit or cease activities that worsen symptoms (Devins, 1989). Because intrusions often stem from various aspects of illness other than disability, illness intrusions cause psychological distress (Abraido-Lanza \& Revenson, 2006).

Because of pain and disability, arthritis interferes with homemaking and other roles, including paid work, religious activities, recreation, and social relations. The high rates of depression observed among arthritis samples may be due, in part, to the inability to perform valued activities. Studies of people with rheumatoid arthritis report that satisfaction with the ability to perform important role activities predicts psychological adjustment, that illness intrusions into these activities relate to depressive symptoms, and that a sense of competence mediates the relationship between arthritis illness stressors and psychological adjustment (AbraidoLanza, 1997, 603). 
Social identity theory provides a framework for understanding why illness intrusions result in psychological distress. Illness intrusions can "be conceptualized as stressors that threaten social role identities, which are crucial components of self concept” (Abraido-Lanza \& Revenson, 2006, 225). Social roles form the basis of self concept, but some roles are more central to identity than others. These central roles have a stronger impact on psychological wellbeing than do less important identities (Thoits, 1991). In short, because they intrude upon the ability to perform important roles, rheumatic diseases threaten individuals' self-concept, ultimately leading to psychological distress and in some cases, depression.

In my research, it is important to understand the effect of illness intrusions on psychological adjustment to arthritis and other rheumatic diseases. Illness intrusions effect individuals' social roles, but also the presentation of oneself. Thus, how persons with arthritis perceive his or her personal social identity might affect his or her attitude toward arthritis and various coping strategies (e.g. self-management programs).

The questions which led to the research discussed in this paper required a qualitative approach. My purpose is to gain an understanding of what it is like to live with a chronic disease, specifically arthritis. I am concerned with pathology, and the frequency and type of signs and symptoms, only insofar as they relate to how these influence health-related beliefs and behaviors. In many respects, this research parallels the 'patient-centered' approach, and raises similar problems around how questions might be formulated so that patients feel able to speak about their experiences. Furthermore, patients' experiences might influence 
intervention approaches, like self-management programs or other strategies, and also change how such programs are promoted.

An important feature of this process is showing patients that their selfreported experiences are valued as research resources. Another important aspect is showing people with arthritis how their experiences might be taken into account in the organization of their care. 


\section{CHAPTER 3: ARTHRITIS SELF-MANAGEMENT PROGRAMS}

Two similar self-management programs are available to help people with arthritis learn strategies for coping with their disease. Both the Arthritis Foundation Arthritis Self-Help Program and the Chronic Disease SelfManagement Program have been proven to be effective at improving selfconfidence and quality of life among people with arthritis (Lorig, et. al., 2001, 2005). "Course content includes: 1) knowledge about the major types of arthritis, nutrition, and use of medication; 2) skills for improving function, decreasing pain and negative emotions through the use of cognitive restructuring techniques and physical activity; 3) problem-solving for health-related problems; and 4) techniques for improving communication with family and physicians" (Lorig, et. al., 2004, 347).

Keysor et. al. (2003) found that peoples' perceptions may influence the strategies they use to manage their conditions. Patients' beliefs about their disease and its treatment have been said to be central to adherence (DiMetteo, Haskard, \& Williams, 2007). The Health Belief Model first viewed beliefs as predictors of preventive health behavior, and included perceptions of "the threat posed by illness, comprised of the likelihood of its occurrence (perceived susceptibility) and its potential for causing physical harm and interfering with social functioning (perceived severity)” (Bowen, Helmes, \& Lease, 2001, 34). 
Overall it can be observed that self-care as a means to cope with arthritis is molded by a combination of gender, objective need variables that indicate poorer health status, and the integration of health beliefs. Most salient is the belief that a general state of health is important to individuals coupled with the belief that they are not doing a good job taking care of their health. This finding is consistent with a family of social psychological models of health behavior (e.g. health belief model, theory of planned behavior, and theory of reasoned action) that emphasize the primacy of subjective evaluation of health, health decision making, and individual motivation (McDonald-Miszczak \& Wister, 2005, 854).

Therefore, if a person with arthritis perceives their health status or disease progression as harmful, he or she is more likely to participate in selfmanagement strategies. Perceptions of health, especially behaviors associated with response to illness, have also been identified as predictors of self-care. Thus if health is perceived as threatened or as declining, self-care activities are often initiated to prevent or manage the illness and delay disability (McDonaldMiszczak \& Wister, 2005).
Along these lines, motivation can be viewed as a process that involves all of the factors that influence behavior. ...the majority of theories and models of human behavior view behavior change as influenced primarily by two factors: 1 ) the perceived importance of behavior change and 2) the belief that behavior change is possible (i.e., self-efficacy). These two factors are thought to contribute to motivation, which then influences behavior (Jensen, Nielson, \& Kerns, 2003, 478).

Motivation to participate in self-management strategies comes from a sense of validation in social roles within everyday life. A constant validation is important to the psychological well-being of people with chronic diseases. Just being reaffirmed in daily activities is a necessity for many. “...for most individuals, maintaining the organization of the self - that is, self-concept - means empirical validation in daily life" (Charmaz, 1983, 170). Facing everyday challenges because 
of arthritis might increase an individual's motivation to participate in selfmanagement (Jensen, Nielson, \& Kerns, 2003) or adversely, voluntarily withdraw into the illness (Charmaz, 1983).

As discussed earlier, people with chronic illnesses are highly concerned with their social identities. If a person with arthritis faces limitations in roles found to be important, he or she could experience feelings of loss (Oatley \& Bolton, 1985). "Thus, role importance moderates the effect of illness intrusion on psychological well-being in part, by affecting self-esteem and a sense of competence" (Abraido-Lanza, 1997, 604). Handling such dilemmas in order to maintain positive evaluations of self and continue prior relationships with others prompts the ill person to develop new strategies for negotiating his or her position (Charmaz, 1983).

Social-role selves do not have rights (to privacy, autonomy, and self-determination), but duties and obligations to perform their role well for the larger units... Consequently, the failure to perform one's role as wife, mother, father, husband, daughter, or son is a failure to be a person at all: Role failure or violation is the loss of the self" (Landrine, 1992, 410).

Self-esteem is the perceived worth attributed to oneself, derived from one's past, present, and potential roles. A loss results in depression when it completely undermines a person's self-worth, and he or she has no other source of worth from alternative roles (Oatley \& Bolton, 1985). According to the Health Belief Model, the performance of health behaviors is strongly influenced by belief in outcome (outcome expectancy) (Hammond, 1998). "Unless people believe they can produce desired effects by their actions, they have little incentive to act or to persevere in the face of difficulties" (Bandura, 2004, 144). 
Bandura (2004) found that the perceived severity and susceptibility to disease in the Health Belief Model are the expected negative physical outcomes. The perceived benefits are the positive outcome expectations. In the theory of reasoned action and planned behavior, attitudes toward the behavior and social norms produce intentions that are said to determine behavior. Attitude is measured by perceived outcomes and the value placed on those outcomes.

Therefore, a person's social identity might influence his or her attitudes toward their own disease or social role expectations. "The degree to which an individual is handicapped depends on the perception of the importance of the role that can no longer be filled" (Car, 1996, 944). The perception of role expectations and the fulfillment of those expectations are influenced by relationships with others (Oatley \& Bolton, 1985). Social support is important in performing health behaviors (Strating, et. al., 2006).

Ajzen (1991) proposed the theory of planned behavior, which is the link between attitude and behavior. He proposed three determinants of intention: attitude, subjective norm and perceived behavioral control. "Attitude is conceptualized as the positive or negative evaluation of performing a specific behavior" (Strating, et. al., 2006, 52). Thus, a person with arthritis is influenced not only by their own perception of the disease, but by others' expectations of them. Coping is defined as "constantly changing cognitive and behavioral efforts to manage specific external and/or internal demands that are appraised as taxing or expecting the resources of the person” (Revenson \& Felton, 1989, 344).

Because it is not known whether the use of various self-management strategies is influenced by "episodes of acute pain or discomfort; functional loss; 
cultural factors; or intentional, preventive, precautionary measures" research into the social identity of a person with arthritis is necessary in understanding motives for coping with their disease (Keysor, et. al., 2003, 730). My research looks into how a person with arthritis views their disease within their selfconstructed social identity.

Using qualitative framework, I interviewed participants by use of ‘judgment sampling' (Burgess, 1982), where study subjects are chosen because it is likely that they will have detailed knowledge of the topic under study, and thus will be able to help the researcher to explore the research questions posed.

Abraido-Lanza and Revenson (2006) explore role-related stressors and psychological adjustment among people with arthritis. Their findings "support the proposition set forth by identity theory that relative to unimportant identities, disruptions to important identities are more psychologically disturbing” (p. 229). To build on these findings, I attempted to relate a person's social identity with the perception of arthritis self-management.

Despite general agreement that self-management is required for control of chronic disease and for prevention of disease complications, it is sobering that across chronic diseases, patients generally do not adhere well to self-management regimen recommendations (Glasgow et. al., 2000, 560).

Lorig et. al. (2004) found that arthritis self-management programs have been underused for several reasons. First, most self-management programs are labor-intensive, and because there is no reimbursement, the programs are largely given outside of the mainstream healthcare system. Second, it could be that large numbers of people cannot or will not attend group education programs. Third, logistic problems could make it difficult to get the person with arthritis and 
program together at the same time. In addition, the underutilization may be due to "misperceptions about the manageability of arthritis, previous advice not to exercise, lack of knowledge about the existence and benefits of these programs by both healthcare professionals and people with arthritis, and other potential barriers to participation" (Brady, et. al., 2003, 59).

In fact, only 1 in 10 Americans with arthritis have ever participated in selfmanagement programs. Recently, the Centers for Disease Control and Prevention explored this issue with people with arthritis using focus groups. When asked what would motivate them to take a self-management course, many participants said they would be interested in enrolling if they could learn to reduce their arthritis pain. More than half of them also said they would be interested in selfmanagement courses if they could learn how to exercise safely, improve mobility, take control of their disease and were able to share their experience with other people with arthritis. Strating et. al. (2006) notes that the overall goals of arthritis self-management programs are to enhance patients' knowledge about arthritis, improve their health behaviors and improve health outcomes.

Keefe et. al. (2000) created the idea that there are five stages of change in relation to the adoption of arthritis self-management strategies. The following stages (p. 304) directly relate to the Heath Belief Model and people's perception of their arthritis and the understanding of self-management programs. 
Precontemplation

Contemplation

Preparation

Action

Maintenance
The individual is not intending to take action in the foreseeable future. People in this stage tend to be unaware that they have a problem and are resistant to efforts to modify the behavior.

Individuals are intending to take action in the foreseeable future. They are aware that they have a problem and are seriously thinking about resolving it, but they have not yet made a commitment to take action in the near future

Individuals are indenting to take action in the immediate future and have taken some small action steps in the recent past. This is the stage of decision-making. Individuals have made a commitment to take action very soon and are already making small behavioral changes.

Individuals who have made overt changes in behavior in the recent past. They are making notable overt efforts to change.

Individuals who have sustained overt changes over time. They are working to stabilize their behavior change and avoid relapse.

The perception of disease severity and interference with life activities might influence what stage of change people with arthritis fall into.

The Centers for Disease Control and Prevention also found that people with arthritis do not want to waste their time on any programs that are not providing new information and proven benefits. Many have an attitude of "show me the results" which influences their receptivity to the program concept. However, arthritis self-management programs have been proven to decrease arthritis pain by 20 percent (Lorig, et. al., 1999, 2005).

My research tries to understand how a person with arthritis perceives his or her own social identity in relation to the promotion of arthritis selfmanagement programs. All the participants chosen for this study were asked to reflect on their experiences with arthritis in depth. In addition, I conducted field 
observation to further explore how participants' self-reported experiences might be seen in daily, routine activities. 


\section{CHAPTER 4: EXPECTATIONS}

In regards to this study, I did hold some expectations. I expect that people with arthritis do not participate in self-management programs for several reasons. First, people with an "invisible illness" like arthritis strive to be seen as "normal" in their social identity (Charmaz, 1993). Admitting handicap might negotiate a person's place within their social identity.

Next, I believe the promoted message of arthritis self-management programs is not aligning with the perceived needs of people with arthritis. If the message of self-management programs promised people with arthritis help in staying part of a social role longer, participation or interest might increase. Matthews and Harrington (2000) asserted that people with "invisible illness" are "actively engaged in impression management and may...(go) to great lengths not to appear disabled” (p. 412). Thus, self-management programs should identify with the attitudes people with arthritis have towards their disease and their social role identity.

The major challenge in assessing patients' experience of disease impact lies in its uniqueness to individuals; individuals perceive and weight aspects of their lives in ways which are particular to them. Most existing instruments have failed to take account of this, imposing standardized models of functional disability, quality-oflife or handicap (Carr, 1996, 928).

Therefore, it is important to attempt to change how people think about their illness and themselves and how their thoughts feed into behavior (Newman, Steed, \& Mulligan, 2004). To produce lasting behavior change, a person's social 
environment must be taken into account, and plans made for ongoing support of self-management behaviors (Gallant, 2003). 


\section{CHAPTER 5: HEALTH COMMUNICATION}

While most promotion of arthritis self-management programs is done through grassroots efforts, the understanding of the perceived message affects people's behaviors. Arthritis and other rheumatic conditions have only recently been addressed as public health problems. "Public health efforts for chronic diseases have historically focused on leading causes of death. Arthritis is primarily a quality-of-life issue because it is usually nonfatal and incorrectly viewed as being an inevitable part of aging, affecting only older people, and having no effective treatment" (Brady et. al., 2003, 45).

Public communication about disease causation and the inherent links to societal versus individual responsibility has also sometimes been examined in published communication research, emphasizing that too little attention has been given to the communication processes associated with forming beliefs about responsibility (Parrott, 2004).

Anyone who has made an effort to change even one habit or behavior knows how difficult behavior change is. Maintaining behavior change can be even more difficult. In self-managementbased pain treatment, patients are expected to make many such changes, often simultaneously. Because learning and then practicing chronic pain self-management is very challenging, the changes necessary for adaptive pain management are unlikely to occur in the absence of significant patient motivation (Jensen, Nielson, \& Kerns, 2003, 477).

People with chronic diseases are often influenced by sources of social support including work environment, media, public policy, and other neighborhood and community factors (Glasgow et. al., 2000). More public awareness and education about arthritis and other chronic disease might then 
make arthritis part of societal norms. The message of arthritis self-management programs should seek to motivate people to keep their social identity and then, reinforce the message of self-management strategies.

In the direct pathway, media promote changes by informing, modeling, motivating, and guiding personal changes. In the socially mediated pathway, the media link participants to social networks and community settings. These places provide continued personalized guidance, natural incentives, and social supports for desired change (Bandura, 2004, 150).

How people think about their disease evolves over time, based on personal experiences with diseases and social, cultural information acquired through education, media, social modeling and social comparisons (Shiloh, 2006). Greater knowledge about one's disease and fulfilling social roles might lead to changes in behavior for individuals to better manage their disease. This again relates back to the stages of change, as posed by Keefe et. al. (2000). Green (1999) found that the acceptance of health education and health promotion depends on its presentation of concrete, specific, achievable, evidence-based objectives. Ironically, a key message of arthritis self-management programs is the proven findings: reduction in pain, improvement in functioning and quality-oflife, and the delay of disability among persons with arthritis (Centers for Disease Control and Prevention, 2005). Yet, participation in such self-management education is low for both men (10\%) and women (11\%) (Theis, Helmick, \& Hootman, 2007). In the literature on health promotion, there is growing recognition that patients may be at different stages of change with respect to the adoption of self-management strategies (Keefe et. al, 2000). There is also an increasing awareness that health promotion efforts can be more effective if they 
are tailored to take into account the individual's stage of change (Velicer et. al, 1995).

Non-directive, conversational interviews were used in order to enable the participants, as far as possible, to reflect on matters of concern to them. Specifically, participants were asked about daily challenges, self-management strategies, perception of arthritis self-management strategies, and how arthritis influences their behaviors. 


\section{CHAPTER 6: METHODOLOGY}

The preferred method of research for this study is qualitative methodology, specifically a combination of in-depth interviews and ethnographies. The qualitative research methods will not be generalizable to the entire population of people with arthritis. However, this study provides insight into people's perception of their disease and how daily life is affected by arthritis. In order to understand how a person with arthritis perceives his or her own social identity in relation to the promotion of arthritis self-management programs, I used interview techniques to probe into sensitive issues. Then, in order to ensure validity, I also became part of the participants' life, using ethnography.

Qualitative research is often said to be naturalistic. That is, its goal is to understand behavior in a natural setting (Draper, 2004). Qualitative research seeks to understand and explain beliefs and behaviors within the context that they occur (Denzin \& Lincoln, 2003). The meaning of words and communication styles vary with time and culture. It is important to understand the context within a particular scene. Not only is the message important, but the people communicating the implied social structure - "discourse, subjectivity, and context” (Jensen \& Jankowski, 1991, 19). Both qualitative methods that I used allow triangulation for maximum data collection.

Christians and Carey (1989) outline four criteria that guide qualitative research. First, the naturalistic observation is based on the Chicago School of thought that "social feelings (attitudes and sentiments) and lifestyle are most feely expressed in actual situations, and must be recovered unobtrusively through 
participant observation, from personal documents, and by open-ended interviewing” (Jensen \& Jankowski, 1991, 361). Second, contextualization says that context allows us to frame the content. Third, maximized comparisons is another criteria given by Christians and Carey (1989) which warns to consider all elements as factors which influence. Finally, sensitized concepts "formulate categories that are meaningful to the people themselves, yet, sufficiently powerful to explain large domains of social experience" (Jensen \& Jankowski, 1991, 369). These categories are the building blocks of observation and interpretation.

\section{In-depth Interviews}

In-depth interviews are useful in obtaining information from a small group of respondents. Semi-structured interviewing allowed me to probe into sensitive issues regarding limitations caused by arthritis or shortcomings within social roles. Here I choose to disclose that I have had rheumatoid arthritis for more than 25 years, since I was diagnosed as a small child with juvenile rheumatoid arthritis. Because of this shared diagnosis, I feel my line of questioning was more direct. However, my diagnosis also posed a threat to validity. I used precautionary measures to ensure that I did not lead the participant. "...avoid posing questions in such a way that they communicate what you believe to be a preferable answer" (Lofland \& Lofland, 1984, 86). My own experience and beliefs did not interfere with the interview.

Everyone wants others to think favorable of them so behavior is tailored to make a person desirable or accepted (Karp, 1980). But because of my own experience with arthritis, I feel as if I share similarities with some of the respondents. My understanding of situations and behaviors differ than someone 
without arthritis. Participants might have felt more comfortable around me and thus, willing to share deeper insight into their social identities.

I recruited 9 participants from a local rheumatology clinic, provided the help of a physician, ensuring that each has doctor-diagnosed arthritis, or another rheumatic condition. Participants ranged in age from 25 to 83 years and were both male and female. Each participant presently served a different social role than others chosen. I accepted participants that have and have not participated in arthritis self-management programs.

In order to weigh the validity of each interview, I looked to "different kinds of evaluative data: 1) the informant's current emotional state, such as anger, fear, anxiety, or depression; 2) the values of the informant, that is, the feelings that may be presumed to underlie opinions, attitudes or behavior; 3) the informant's attitudes or sentiments, his emotional reactions to the subjects under discussion; and 4) the informant's opinions or cognitive formulation of ideas on a subject" (Whyte, 1982, 111). Again, I am aware that by me conducting the interviews, participants want to share personal accounts or compare prognosis. The participants' perceptions of me could have influence the information I received.

Neutrality and the elimination of bias are basic methodological concepts in sociology... Membership and the application of one's own cultural experience and understanding to research problems are often frowned upon as too "subjective" or "slanted" (Hoffmann, $1980,50)$.

Being aware of this potential problem reminded me to be reflexive when examining the data.

Prior to the interview, I asked participants to answer a questionnaire collecting demographic and disease specifics. Researchers from Harry S. Truman 
Veterans' Memorial Hospital at the University of Missouri provided me with the enclosed questionnaire (See Appendix I). It is consistent with the ongoing rheumatoid arthritis study (Burks, Smarr, Laffey, 2006). Working on the assumption that some interview structure is inevitable (Brown \& Williams, 1995) and useful, a topic guide was developed from existing literature in order to provide a basis from which interviews must proceed (See Appendix II).

Each interview lasted between 30 and 60 minutes, as to be aware of participants' needs. I interviewed each participant in his or her normal lifestyle routine. For example, I recruited a working professional. Therefore, I conducted my interview at his workplace. The interviews were taped, with the participants' permission. The interviews were then transcribed verbatim by the researcher.

\section{Ethnography}

To ensure that I am a neutral participant, I have chosen to combine indepth interviews with ethnographies. By using triangulation of these two methods, I explored topics I observed in relation to social identity and selfmanagement strategies. Thus, the answers I received from in-depth interviews are complemented by my observations in the field. And, probably having experienced like situations, I hope to better understand the role arthritis plays in their lives, unique to a particular social identity.

Ethnography allowed me to observe participants in natural settings partaking in routine daily activities. Naturalistic observation does not interfere with the people or activities being observed (Denzin \& Lincoln, 2003). In order to conduct ethnographic research, I immersed myself into the social identities of my participants. I made observations, took fieldnotes, and considered themes. Using 
triangulation, I looked for deeper meaning in my ethnographic observation about a topic that might have drawn interest during previous interviews.

Both of these qualitative methods provided insight into how an individual's perception of his or her disease within different social roles affects the attitude held toward self-management programs. Observing and exploring the 'why' allowed me greater access into the minds of people living with arthritis. While both the Health Belief Model and the Social Identity Theory were used to explain any phenomena - I suspected that much meaning would take shape on its own. 


\section{CHAPTER 7: IMPLICATIONS}

The implications of this study vary. Since my expectations were met, I foresee arthritis self-management programs being communicated differently to people with arthritis. Perhaps the format will communicate ways to fulfill social roles or stay in those roles longer. While both the Arthritis Self-Management Program and Chronic Disease Self-Management Program both contain information about function and mobility, the results of this study might allow for that information to be personalized for various social roles. The challenge for us is to consider how to develop imaginative ways of both facilitating patients' accounts of personal experience and, importantly, of incorporating the insights provided through these accounts into care plans and clinical practice. Also, one may be able to enhance the outcomes of self-management interventions for arthritis by tailoring treatment to the person's particular stage.

However, I feel as if the research methods also provided insight into people's perceptions of their own chronic disease. Often, physician and health care professionals are not aware of the limitations - both physical and mental that arthritis causes (Beiseker \& Beiseker, 1993). The doctor-patient relationship is often unbalanced on both ends, making communication difficult. Expressing pain and anxiety can be difficult in a clinical setting. Thus, this research provides data about the patient - a side that is often not heard. The data collected facilitates better physician understanding of the emotional aspect of living with a crippling disease. Future research should identify with people with arthritis on better strategies to encourage the use of self-management programs. 


\section{CHAPTER 8: DATA AND ANALYSIS}

In this study, a total of nine participants were interviewed - six female and three male participants ranging in age from 25 to 83 years. Eight of the participants were doctor-diagnosed with rheumatoid arthritis, one with osteoarthritis, and five had co-morbidities. The average length of disease duration was almost 12 years, ranging from 3 to 30 years duration.

Because of the recruitment process, all participants were patients of a local rheumatologist in Columbia, Missouri. Regular visits to the rheumatologist ranged from just twice each year to more than six visits annually. No participants were in remission so each had at least some disease activity.

Six of the participants reported having at least a college education. Seven participants were married, or had been at one time. Appendix III shows each participant's demographic information.

As congruent with qualitative data, themes and patterns provide insight into the phenomena being study - how people with arthritis perceive their illness in relation to social roles filled and how that perception influences participation in self-management programs. Both the data and analysis are intermingled according to found themes and patterns.

A chronic disease like arthritis affects all aspects of a person's life. Adjusting to arthritis is a process, especially considering the different stages of the disease but also, a person's ever-changing social role in life. The data found in this study identifies with people with arthritis and discusses disease from a patient's perspective. 


\section{Social Roles and Realization of Identity}

Arthritis is sometimes called an "illness intrusion" which interrupts people's lives in all capacities, not just physically. Besides adjusting to the physical impact a chronic disease may have on the body, people with arthritis also must learn to live with the disease in all aspects of reality. This might include adjusting to the diagnosis mentally or coping with emotions that come with a chronic disease. In addition, while people with arthritis must adapt to the disease, their support system must also do the same. Chronic disease affects all aspects of daily life - mental, emotional, physical, and quality of life.

Participants were asked about the original diagnosis of the disease, specifically their emotional and mental state of mind. Participants were encouraged to talk about what else might have been going on during that time. Eight participants reported feelings of ‘depression' or 'anger' and two equated diagnosis with age. One participant (Female, 25) said: "My grandma has arthritis... I always just imagined it being something I would get when I was old." Another participant (Female, 42) said: "Never did I think I had arthritis. I mean, I am so young!"

Talk about the diagnosis. How did you feel? How did you react to the diagnosis?

Is still 'reacting' to diagnosis and reports limitations. Feels 'sad' and 'depressed' when limited. (Female, 25) - "It sucks not being able to do what I used to do... even like two years ago. It's hard letting go.”

Reports feeling 'depressed' and 'guilty' because of limitations in social roles of wife and mother. (Female, 42)

Says arthritis comes with age. (Female, 57) 
Reports feeling 'depressed' and 'had to learn to cope.' Afraid of being a 'burden' to children. (Female, 66)

Says arthritis comes with age. (Female, 68) - "I guess I was thankful it [diagnosis] wasn't something more serious."

Reports feeling 'devastated' and 'scared' after diagnosis. (Female, 83) - "I was angry for a long time. I had a really poor attitude about the whole thing [diagnosis].

Reports feeling 'depressed' and 'sad' after diagnosis. (Male, 38)

Reports feeling 'upset' and 'afraid' of diagnosis. (Male, 47) - "Hearing the word 'arthritis' is enough to scare anyone, especially someone my age!"

Avoids 'thinking about' diagnosis and does not share with anyone outside of close family. Feels 'depressed' because of limitations in social role of husband and caregiver. (Male, 72) - "It's [diagnosis] not something I think about often."

Six of the participants were married at the time of diagnosis, calling their spouses 'supportive' and 'understanding.' One participant (Female, 42) says of her husband: "He's been nothing but supportive. Does things when I can't. He knows when I'm not feeling the best. Or, when I'm stiff. He always takes care of me. Or, of the kids." Another participant (Male, 47) said: "She [wife] is very understanding. More so than I ever would have imagined. More so than I would have been. She is truly an amazing woman. I got lucky. She supports me and really takes care of me." Participants often placed themselves in a role of need. This is ironic, however, since later it is noted - most participants are willing to 'cross the line' and 'over do it' when fulfilling a social role. Thus, spousal support is really necessary at times when participants have 'crossed the line' and pushed their limitations. 
How did your spouse react to the diagnosis? How did your children react?

Husband is 'supportive.' Calls children 'understanding of limitations' but too young to understand prognosis. (Female, 42) - "If I over do it one day, the next is always rough. I'm really stiff. My bones hurt. Or, my joints. Whatever. I'm in pain. Very, very stiff. Can't hardly move or get out of bed. On days like those, it's hard to care for my children or to take care of our home."

Husband 'supportive.' (Female, 83) - "At the time [of diagnosis] we were both scared. There were so many unanswered questions."

Thought wife was 'supportive' but blames diagnosis of arthritis for demise of his marriage. Too limited by the disease. Child understands pain. (Male, 38) - "I don't want it [arthritis] to affect my life at all... in a negative way. So, sometimes I over do it [in order to compensate].”

Wife is 'understanding' and 'supportive' of diagnosis, often acts as participant's caregiver. Does not discuss diagnosis with children. (Male, 47)

Wife has arthritis and felt 'depressed' upon participant's diagnosis. (Male, 72) - "It was hard to know that now, I might not be able to care for [wife] as I would have healthy."

One participant (Male, 38) blamed the diagnosis for his divorce. He says: "I only found out later, after we got divorced, that she [ex-wife] really wasn't okay with it [arthritis]. She didn't like the arthritis because it limited what I could do.” Several participants reported feelings of 'guilt' for daily limitations within the household or not fulfilling social roles.

All participants report feeling limited by the disease, specifically pain or side effects from medications. One participant (Female, 66) said: "So many of my medicines make me sick. Almost nauseous. I've gained a lot of weight because of the Prednisone [steroid].” In regards to pain, another participant (Female, 57) said: "It [arthritis] tells me what I can do, like getting out bed, exercising, 
landscaping, or even to the most simple things like picking up my house or taking out the garbage."

Often, these limitations interfere with participants' lifestyles. Because of the unpredictable conditions of the disease, people with arthritis often suffer disruptions of their lives and selves that go far beyond the physical discomfort they experience (Charmaz, 1983). Every participant was aware of his or her limitations and governed daily activities by the amount of pain and stiffness felt. A participant (Male, 38) explained: "I don't put myself in situations like that. I'm not running around playing tackle football anymore. No basketball or things like that where... because I've learned that I could do it, but then I'm going to pay for it the next week. I'll be sore and hurting. So, I don't put myself in situations like that." Once valued lifestyle activities are limited due to the disease.

Two participants reported feeling content with their current condition and health status. One participant (Male, 72) said: "I haven't had any real bad spells... at least, not yet." Both participants were not in remission and experienced pain daily, but not enough to feel limited in daily activities.

Talk about your experience with arthritis. Remission? Medications? Limitations? Challenges?

Thinks arthritis is a disease for the elderly. Limited by pain. Prevents her from being 'active.' Experiences side effects from medications, often causing her to be absent from work. (Female, 25) - "I think I'm most limited by the pain. My left knee hurts all the time. It prevents me from being as active as I used to be."

Reports taking 'so many medicines' and feeling pain and stiffness. She is aware of her limitations. Talks about not 'overdoing' it. (Female, 42) - "I try not to over do it. Sometimes, I can't help it. It just happens." 
Says her lifestyle is 'limited' by the disease on a 'day-to-day' basis because of its unpredictable nature. Has experienced side effects from medicines. (Female, 57) - "Arthritis is limiting but, for me it's on a day-to-day basis. I might wake up tomorrow and not be able to get out of bed but then Friday, I'll get out of bed and walk around the neighborhood."

Disease has progressed since diagnosis, causing more pain and limitations. Reports side effects from medications. (Female, 66) - "I can't move around well. Takes me a lot longer to do anything now. Like, I can't get out of my chair very fast. Always takes me a while. Or, I had to move my bedroom to the main level. Just can't climb the stairs."

Says she is 'doing well' although not in remission. (Female, 68) - "It's been several months since I've had a flare.”

Experiences limitations with hands. (Female, 83) - "It's just a headache. Something that's there. A constant pain. And now, my joints are really starting to ache. Can't knit for long before my hand cramps up. My toes don't fit in certain shoes anymore. I can only buy New Balance."

Reports side effects from medicines. Experiences pain daily. (Male, 38)"It [arthritis] controls the way I live and what I can and cannot do."

Says 'biggest challenge' is seeing the 'physical deterioration' of his body. Has bouts of depression. Feels 'insecurities' about the disease. (Male, 47) - "I think depression is my biggest challenge. It's so hard dealing with the physical deterioration of the body."

Experiences 'nagging pain' in joints, mostly his knees. (Male, 72) - "I have constant nagging pain in my joints, mostly my knees. I have times where I really hurt."

Arthritis is unpredictable and often can disrupt a person's life and self far beyond the physical discomfort he experiences. All participants discussed limits to daily activity, as told by their level of disease. Six participants felt as if the disease completely dictated their life course, dependent on active symptoms. One participant (Female, 57) said: "Basically, even though this isn't entirely true arthritis is my boss. I don't always listen, but then I feel the wrath. So, I try to listen.” Three participants just 'deal with' the symptoms. One (Female, 42) said: "I deal with the arthritis as best I can. It's hard. It can be really hard." Two 
participants noted that the prognosis 'could be worse.' One (Female, 57) said: "I

have arthritis. So do a lot of other people. And my thinking is that, no matter

how much I hurt - things could be a lot worse."

\section{What role does arthritis fill in your life?}

Says she has to 'live with it.' Does not know how to deal with the disease both physically and mentally. (Female, 25) - "I have it [arthritis] and I have to live with it."

Reports that arthritis rules her life. (Female, 42) - "I think arthritis is my life. It tells me what I'm able to do that day. To me, arthritis is just a reminder of limits. Whatever my arthritis tells me that day... I do."

Calls arthritis her 'boss.' (Female, 57) - "It [arthritis] tells me what I can do.”

Says she is 'mindful' of arthritis daily. (Female, 66) - "It [arthritis] is something I am mindful of. I know my limits and I try not to cross the line."

Reports planning around arthritis. Dependent on daily symptoms. (Female, 68) - "I plan around my arthritis. Some of the medicines only can be taken at certain times or having to go in regularly to see [rheumatologist] or have blood work done. Or, depending on how Ifeel any particular day... It all just depends on what my body feels."

Calls arthritis a 'constant pain' and says it dictates her schedule based on daily symptoms. (Female, 83) - "A lot of times, arthritis dictates my schedule or activities just based on how I feel that particular day."

Says he just 'deals with it' and understands his limitations. (Male, 38) - "I look at it this way - it's better to enjoy life and have to suffer through some pain a couple days later than to not enjoy it."

Reports feelings of 'depression.' Does not know how to deal with the disease mentally. (Male, 47) - "For me, I don't know how to deal with it [arthritis]. I have bouts with depression. It [diagnosis] is such a difficult thing to deal with... the deterioration of your body... of your abilities... It's just hard." 
Reports 'just dealing with it.' (Male, 72) - 'I'll give you this example, if you broke your leg - it would be very painful and intrusive in your life... may even leave you on the couch one day. But, life goes on. A broken leg doesn't mean you still can't live or do all the things you normally would do. I think of arthritis as the same thing. Just deal with it as it comes and don't make it more of an issue than it already is."

Although participants acknowledged the role of arthritis in their lives, most downplayed their symptoms comparing themselves to others with lifethreatening illnesses, like cancer. Most believe that arthritis is common and people just have to accept the condition. One participant (Male, 38) said: "If I'm having a flare up... you know, I just deal with it. I don't really have a choice." Another (Female, 42) said: "I might wake up and be incredibly stiff. So, instead of making breakfast right away or getting [husband] out the door, I go sit in a hot bath. Try to loosen the joints."

Most people fulfill a number of significant social roles. Such roles give humans meaning and purpose. Participant's social roles were both shared, like parent, spouse, or friend; but also different, like grandfather, daughter, or employee. Asked how arthritis has changed or shaped participants' relationships, common words used by the participants in order to describe themselves included 'burden' and 'dependent,' while others used 'supportive' to describe family and friends. One participant (Female, 42) said: "[Husband] does what he has to do. He takes care of me and the kids. He fills in the gaps."

\section{How has arthritis changed (or shaped) your relationships?}

Reports feeling awkward about her disease. (Female, 25) - "My mom worries about me more now. I worry about myself. Like, with a job - I have to have insurance that will cover me and... anything that might happen in the future. I try to keep it [arthritis] to myself. I mean, I know I'm in pain or can't do certain things but, I don't talk about it a lot. Ijust deal with it." 
Feels 'dependent' on spouse which 'scares' and 'worries' her. (Female, 42) - "I feel more dependent on [husband] now. For the most part, I try not to complain. Pain is just a constant in my life now. Some days are good and others aren't. That's my life now."

Blames her disease for never marrying. Reports asking others [friends and family] for help. (Female, 57) - "I don't think of myself as invincible anymore. Quite the opposite. I need... and askfor... help. I have come to rely on my support system more."

Relies on others for care and support. (Female, 83) - "Now, I think we all [friends] rely on each other. In the community, we are al friends. We try to take care of each other... to help."

Blames arthritis for his divorce and other destructive behaviors. Reports feelings of 'depression' which affect his attitude. (Male, 38) - "[Girlfriend] is really supportive. We're open [about the disease symptoms]. Say, 'my shoulder is killing me' or something like that. I mean, she's supportive to the extent that she can be but there's nothing she can do. If I feel crappy... I feel crappy."

Reports feelings of 'depression' when faced with limitations. (Male, 47) "Ifeel as if the diagnosis of arthritis has shaped my relationship with my wife. We have had to work through all the challenges, like morning stiffness or problems in the bedroom or being too tired or worn out to take the kids to the park. Life has changed a lot since I was diagnosed."

Reports being 'reliant' on his spouse. (Male, 72) - "I think we've become more reliant on each other in the sense that we help each other when we're not feeling well."

Participants all described 'intense' pain due to arthritis symptoms.

However, seven participants believed their pain was not understood. One participant (Male, 47) explained:

"I think now we understand each other, but it's been tough. Just me learning how to cope with the symptoms of the disease. For me, that has been the biggest challenge of all... just getting over myself and my own insecurities. It's me. It's me not expressing myself or asking for help."

While married participants described their spouses as being 'supportive'

and 'understanding,' feelings of guilt and 'depression' surfaced over the diagnosis 
of arthritis. One participant (Female, 42) said: "When I was first diagnosed, it was rough. Not knowing how to talk to [husband] about it or how to explain the pain. Arthritis has changed my life. It sometimes still takes adjusting." Another (Female, 66) said: "I feel guilty that I am a burden to my children."

This research also attempts to understand how people with arthritis perceive themselves within a social world. The social identity is often developed over time, changed by life experiences (Ethier \& Deaux, 1994). Six participants reported that arthritis affects their 'mood' and 'attitude.' One participant (Female, 57) said:

"If I feel good, my whole body feels good. No pain. No stiffness. Then, I'm happy and life is good. But, if I'm not feeling 100 percent... I think people can see that. I try not to let arthritis affect my mood. I know that 'this too shall pass' so, I always think that. No matter how much pain I have... I really believe that things could always, always be worse."

Another (Female, 66) said: "I think any time the body doesn't cooperate or feels pain... I think, as humans, it's frustrating. But, what can you really do other than just cooperate?” Two participants reported not talking about the disease to others. One participant (Male, 72) said: "Outside of [wife], not many people know I have arthritis.” Another (Male, 38) said:

"There was a time when I was first... actually, for like the first 10 years of having it [arthritis]... where I didn't even admit I had it. I didn't tell anybody. I don't know why. I was embarrassed, or something. And I have... kinda come out of that. I'll tell people." 


\section{How does your arthritis affect other people in your life?}

Mood changes according to pain and limitations. (Female, 25) - "I'm sure other people get tired of hearing me whine about the pain. I'm such a wimp!"

Reports being 'moody' due to pain. (Female, 42) - "I keep the disease close. I try not to complain a lot. [Arthritis] affects my attitude. When I'm not feeling good, everyone knows. Facing stiffness or challenges... like when I can't do the laundry - it puts me in a funk. I think it would anyone. Then, I feel like I'm a burden. That someone has to do my job."

Arthritis pain and stiffness affect 'mood.' (Female, 57) - "I try not to let arthritis affect my mood."

Asks daughter for help and support. (Female, 66) - "I think [daughter] feels responsible for me. I am probably making it sound like I need or require a lot of help, but that's not it. I'm very active. Try to stay active. It's just...through the flares... or some of my bad days - I do need help."

Relies on spouse for help. (Female, 68) - "[Husband] does a lot for me. When I'm not feeling well, he knows. He'll cook or clean. He probably feels my arthritis most since he's always around."

Does not want to 'burden' anyone. (Female, 83) - "I think now it's just a matter of keeping it all together... doing what I can and finding someone to help where I can't. I try not to burden anyone. Some days I'm okay and others... I'm not."

Reports that arthritis affects his mood. (Male, 38) - "Well, if I feel bad like any other person - if you're in a lot of pain, you're less likely to be cheery. [Pain] makes you grumpy... have more conflicts in personal relationships with people."

Mood affected by the disease. Experiences feelings of 'anger' and cannot 'accept the diagnosis.' Relies on spouse for care. (Male, 47) - "More than anything, I think it's me that affects people. Me. My mood. My own problems accepting the disease. I'm angry. I just can't accept the diagnosis. I'm working on it, but I get so angry. I see other men... healthy men... I get bitter inside. So angry. I just can't deal sometimes.”

Does not discuss with others. (Male, 72) - "Can you imagine if everyone sat around talking about their arthritis?!?!!"

People with arthritis often experience unpredictable disruptions in life. The inability to completely fulfill a role gives rise to depression (Oatley \& Bolton, 
1985). The perception of one's own social role has been linked to health outcomes. One participant (Female, 25) said: "I try to keep it to myself. I know I'm in pain or can't do certain things, but I don't talk about it a lot. I just deal with it." Another (Female, 42) said: "Ifeel like I'm a burden. That someone has to do my job."

Arthritis has both a physical and emotional impact on a person's life. Five participants named 'pain' as a controlling agent in their lives. One participant (Female, 25) said: "I think I'm most limited by the pain. My left knee seems to hurt all the time. It prevents me from being as active as I used to be." Another (Female, 66) said: “My hands hurt all the time.” Revenson and Felton (1989) found that pain often causes "reduced involvement" in social roles and a "lowered quality of life" for people with arthritis (p 344).

Eight participants were familiar with their limitations and understood what 'crossing the line' meant for their bodies. One participant (Female, 42) said: "If I over do it [physical activity] one day, the next day is always rough. I'm really stiff." All participants talked about 'adjusting' to arthritis physically, but never mentally. One participant (Female, 68) said: "Becoming accustomed to pain all the time and just feeling constantly exhausted - it definitely takes a toll on the body, or at least on mine. It can really be frustrating when your body won't cooperate." Although a few participants reported having a difficult time coming to terms with the diagnosis, only one talked about the mental and emotional components of having arthritis. He (Male, 47) said: "Depression is my biggest challenge. It's so hard dealing with the physical deterioration of your body." Although all participants talked about arthritis pain, disease symptoms 
were just another part of life - 'adjusting' to the disease was most important. No real definition of 'adjusting' may be determined from this research.

\section{Tell me about a time that you thought arthritis was controlling your life.}

Reports knowing limitations and avoiding pain. (Female, 25) - "I don't think arthritis controls my life or ever has... I mean, I've adjusted.”

Feels controlled by pain. (Female, 42) - "I try not to let it but... I think arthritis controls me when I'm in pain. I succumb to it."

Feels controlled by unpredictable flares. (Female, 66) - "Any time I have a flare, I feel controlled. I don't like not being able to do what I want."

Reports not wanting to be a 'burden' to family but often feels controlled by pain. (Female, 83) - "It's frustrating not being able to do what you want, when you want."

Feels arthritis limits his lifestyle. (Male, 38)- "It [arthritis] controls the way I live and what I can and cannot do."

Does not feel controlled by arthritis pain, but reports limitations. (Male, 72) - "Arthritis does not control my life... there's pain... but, I do what I want. Or, try to. If I have to stay home... I have to stay home."

All participants reported feeling 'challenged' by arthritis symptoms. One participant (Female, 57) said: "This [arthritis] is something I must overcome." Common words when discussing the disease included 'dealing' with the pain and not 'over doing it' during daily activities. One participant (Female, 83) said: "I force it sometimes... that hurts more." Another (Male, 47) said: "Dealing with the flares is so hard... It's all very hard to swallow." Another participant (Female, 42) said: "I have limits but I don't ever press it. I listen to my body. I listen to the arthritis.” 


\section{Have you ever felt challenged by arthritis symptoms?}

Reports being 'limited' by disease causing her to feel frustrated. (Female, 25) - "It's challenging when your mind is willing but the body is just not completely able."

Reports feeling 'challenged by pain.' Has learned to 'deal' with symptoms. (Female, 42) - "When I was first diagnosed and I didn't want to take all the pills... the pain was so bad. For about two weeks after my diagnosis, I stayed in bed. I was depressed... I thought my life was over."

Calls arthritis 'obstacle.' (Female, 57) - “That's it. I know I have arthritis. I know my life has changed... and is changing. But, that would have happened anyway, just in... maybe different ways."

Reports limitations at work and 'over doing it.' Calls arthritis 'sporadic' and 'unpredictable.' (Female, 66) - "I can't stand for long periods of time and in my line of work - that's challenging. In fact, it's not okay. I don't want to shirk my responsibilities and then, someone else have to do my work. So, often I used to over do it. Quite a bit, actually. That pain is something that... I can't ever adjust to. One day it's so painful and the next, it's tolerable. Just really sporadic and unpredictable."

Says she is learning to 'deal' with the symptoms. (Female, 68) - "I deal with any symptom just like I would if I had a cold or the flu. It's a learning curve."

Experiences limitations and feels 'frustrated.' (Female, 83) - "When I can't use my hands, I become really frustrated and angry."

Feels challenged by pain. (Male, 72) - "The pain is sometimes a bit much... and to remember to take all my pills..."

As Revenson and Felton (1989) found, the major problems people with arthritis face are restricted lifestyles, limited movements and pain. Although physically challenged by arthritis symptoms, most participants admit that limitations affect their mood and attitude.

"I get down on myself when I can't run as far or as fast as I once could." (Female, 25)

"If I feel good, my whole body feels good - no pain, no stiffness. Then, I'm happy. Life is good. But, if I'm not feeling 100 percent - I think people can see that." (Female, 57) 


\section{Utilization of Arthritis Self-Management Programs}

When asked how participants felt about themselves and their disease, in relation to challenges experienced, all participants felt 'frustrated.' Six participants did not think about their disease while two said they 'hate' arthritis. However, in order to learn how to better cope with arthritis symptoms, doctors and researchers recommend self-management programs. Six participants name 'exercise' as a commonly used arthritis self-management strategy. Three say 'diet' and two list 'taking medication' as important. One participant does not engage in any self-management.

Eight participants report never having attended an arthritis selfmanagement program. One female participant attended a self-management class. She reports learning about the disease and how to exercise properly. However, she does not continue the learned exercises.

"I don't feel as if the program totally applied to me. Sure. Some of the information was very useful... but not all. I just don't think some of the suggestions or recommendations... well, they just weren't for me." (Female, 66)

To the eight participants that had not ever participated in an arthritis selfmanagement course, such programs were not top-of-mind.

\section{Why have you not participated in an arthritis self-management} program? Do you think you would benefit from an arthritis self-management program?

Says arthritis self-management programs are for the elderly or those with more disease activity. Will attend when 'arthritis becomes a factor.' (Female, 25) - "I didn't know there was such a thing [as selfmanagement programs]. Well, I did... but not for people like me."

Does not think an arthritis self-management program would help her condition. Unsure of course content. (Female, 42) - "I don't know what I would learn that I don't already know." 
Does not feel it is 'necessary' or that she would benefit. Unsure of course content. (Female, 57) - "Just don't feel it [self-management program] is necessary. Not sure what I would learn. I don't know. I feel as if I'm doing well just with what I have been doing... so, why change it?”

Does not feel an arthritis self-management program is 'necessary' for her condition. (Female, 68) - "I don't think I need to take one [selfmanagement program]. Not now."

Unsure of course content. (Female, 83)

Thinks he is not 'the typical arthritis person' and would not benefit from an arthritis self-management program. Unsure of course content. (Male, 38) - "Honestly, I don't know that it would be much help to me. I don't think I'm the typical arthritis person."

Does not have time to attend. (Male, 47) - "I have my hands full as it is. Don't think I can squeeze much more on my plate."

Calls an arthritis self-management program 'unnecessary'. (Male, 72) Four participants had not ever heard of arthritis self-management programs being promoted or advertised. Three did not think themselves the target market for such programs. Two participants wanted more information before considering attending an arthritis self-management program.

When coping with a chronic disease, many people seek additional information - outside of their physician's office. Four participants used the Internet to search for general health information, while five only trusted their rheumatologist.

\section{Do you enjoy reading or learning about arthritis?}

"Until mine [arthritis] becomes a serious issue... I can deal with it fine now." (Female, 25)

"I don't want to know the worst-case scenario. That seems like that's all that's out there. I'd like more positive information." (Female, 42) 
"I would like to hear about techniques or suggestions how to do something... how cleaning my house could be easier...” (Female, 66)

"I understand the risks and what's coming down the line. I try not to think about it." (Male, 38)

"I have it [arthritis]. I know about it. That's it... I don't want any more information... outside of what to expect... or what my medicines will do." (Male, 47)

Three participants request arthritis-related information, but personalized to their condition. Eight participants have asked their rheumatologist for more information on arthritis-related topics, like new medications. 


\section{CHAPTER 9: ETHNOGRAPHIC FIELD OBSERVATIONS}

In addition to the in-depth interview date, I also collected ethnographic field observations on each participant. Time spent in the field varied from three to nine hours, including the interview. The data I collected in the field does not have a strong theme or pattern. However, my observations simply enhance the data collected by interview. Below are my field observations.

\section{Asking for help...}

Outside of the home, most participants did not discuss their disease with others. One participant (Female, 66) volunteers regularly and is surrounded by other elderly people. While observing, I noticed a group conversation about arthritis pain and new medications. The participant did not contribute to the conversation, although she was included in the group.

Few ever asked for help from others beyond spouses or children. For example, one participant (Female, 42) was in the process of preparing lunch for her children but was unable to open a jar. After several minutes struggling with the jar, she decided to leave her almost-prepared meal behind and take the children out to eat. Another participant (Male, 38) came to work during a flare and had trouble sitting down at his desk. He tried several strategies to maneuver into his desk chair, but all failed. Finally, he gave up on the idea of a chair and used a stool to sit and work, instead.

Participants did not want to appear 'weak' to others. Although close friends and relatives were aware of the participants' diagnosis, symptoms and issues were not discussed. I observed three participants in the waiting room for 
their rheumatologist and all discussed arthritis-related topics to complete strangers. Later, however, one participant (Female, 68) was at lunch with a friend. When asked about her arthritis, she replied, "Fine" and simply changed the subject.

No accommodations were requested by participants, even on a 'bad day' when symptoms were severe. One participant (Male, 47) attended work in severe pain and did not cancel any appointments. As I observed, he never left his desk chair. By the end of the day, however, he spent 20 minutes trying to stand up straight.

\section{Personal narratives...}

Most of the participants discounted their experiences with arthritis. Although, each participant wanted to discuss with me shared experiences and or symptoms - not one would fully admit the amount of pain felt. After several minutes of discussing painful symptoms, almost all the participants would change the topic of conversation. I felt as if participants wanted to discuss their experiences with arthritis but bordered on sharing too much information and feeling inferior, even though I share the same disease. I noticed that few participants had an outlet in which to discuss their feelings or symptoms.

For the married participants, I observed none discussing the disease or symptoms of the disease. It could be that arthritis-related problems have become a part of daily life and are only discussed when severe. 


\section{Independence...}

Arthritis is unpredictable by nature and often causes disruptions in peoples' lives. However, all the participants - even when in pain - did as much as physically possible to stay part of their social role.

I witnessed two individual participants playing with their children. Both were very active - playing tag, swinging, throwing the Frisbee. However, several hours later, both participants were slow-moving and very stiff. 


\section{CHAPTER 1O: CONCLUSION}

The goal of this research is to understand how people with arthritis perceive themselves in relation to their disease, but also how that perception might influence health-related behaviors. From the data collected, it might be said that arthritis pain is a constant and often a symptom with little, to no relief. Although arthritis remains an active concern to people with the disease and in some cases, may rule supreme, for most - arthritis is 'just a disease,' something that happened and now, must be dealt with - perhaps comparable [in the minds of the participants] to the flu or a broken bone.

The participants in this particular study are very aware of the future prognosis that is so common with arthritis - declining health, immobility, loss of independence - but none embrace the disease. People with arthritis live the disease 24/7 with absolutely no relief and do not want to be interrupted more than necessary. As Devins (1989) points out, "illness intrusions" disrupt an individual's lifestyle. Beyond disease-caused lifestyle interruptions, people with arthritis do not want to be burdened with yet, another disease-related issue, including self-management. But, as the participants noted, self-management techniques are already being performed daily - just not learned through a formal self-management program.

Most felt as if arthritis-related topics or information only address 'worstcase scenarios' instead of personalizing information to various stages of the disease. As Bradey et. al. (2003) found, arthritis is often misunderstood - even by the people it affects. Gerhardt (1990) notes that in the area of long-term illnesses, 
it becomes vital for those [including the patient] involved in care and treatment to know what effects interventions have, not only in clinical terms, but also in terms of an individual's quality of life. In this study, the majority of participants did not believe arthritis self-management programs would benefit them. Moreover, arthritis self-management programs have been proven to benefit people with arthritis in all stages of the disease (Lorig, et. al., 1999). In fact, arthritis self-management programs are designed to educate people with arthritis on how to better understand their disease, cope with chronic pain, and to take an active role in managing their arthritis.

Another common theme in this study is how people with arthritis discussed the prognosis, or dealt with chronic pain. The in-depth interview provided a platform for participants to discuss openly their pain and daily challenges, as caused by the disease. For most, however, daily arthritis pain was inevitable, same for challenges and limitations. But, it is important to note that the participants of this study coped with chronic pain until it became too much to bear. The perception of one's disease changed with episodes of severity. For example, while interviewing a participant $($ Male, 38$)$ he briefly spoke of pain in his right wrist. He compared the pain he was experiencing the day of the interview to pain he felt years prior during an extreme flare up, after which he had both shoulder joints replaced. The pain in which the participant felt on the day of the interview was uncomfortable, but tolerable. The participant had not yet reached his own breaking point, like he referenced with the extreme flare up years prior. So, although the participant did not disclose his pain and discomfort 
to co-workers - he still felt pain, yet it was not enough to cause him to perceive his health status as negative, or declining.

Perception of health status is directly related to how an individual perceives himself or herself within a self-constructed identity (Abraido-Lanza, 1997). Participants noted that fulfilling a social role, like parent or spouse, was ultimately more important than their disease symptoms. One participant (Female, 42) said:

"The diagnosis was very hard to swallow. For me, mostly. But I think [husband] was taken aback by it, too. For a long time - even now - I feel so guilty. I mean, he married me. His wife has arthritis! It would be different if I were older. Or, if I weren't healthy when he married me. I was depressed for a long time. Maybe still am. I just want to be the best mother I can be. Not let this disease get in the way. I want to be the woman [spouse] married. To not have limits."

All the participants were very aware of their limits and also knew the consequences of pushing their bodies too far beyond said limits. However, the majority of participants were willing to 'over do it' to enjoy a valued activity - like playing with their children.

Chronic diseases present a number of threats to the self concept, which can adversely affect psychological well-being (Abraido-Lanza \& Revenson, 2006). The majority of participants used words like 'depressed', 'sad', or 'frustrated' to describe their diagnosis or experience with the disease. As mentioned earlier, social identity theory proposed that social roles, such as being a parent, worker, or spouse, form the basis for identity (Thoits, 1991). Arthritis, however, often impacts the ability to perform various activities, including those required for the fulfillment of various social roles. 
Because intrusions often stem from various aspects of illness other than disability, illness intrusions cause psychological distress (Abraido-Lanza \& Revenson, 2006). Thus, how persons with arthritis perceive his or her personal social identity might affect his or her attitude toward arthritis and various coping strategies, including self-management. For example, seven participants reported having children. However, only four participants had children living at home at the time of being diagnosed with arthritis. All felt they were able to fulfill the role of parent with few limitations or challenges. Thus, the social role of parent had not yet been threatened by the disease. But, for one participant (Female, 57) coping with everyday tasks is difficult, which often causes her to 'feel sorry' for herself or become 'frustrated'.

A role provides an identity and is bound up with personal goals, plans, and expectations... Distress from a provoking agent, therefore, is a species of disappointment, a disappointment of goals to which a person is implicitly committed and by which that person has defined her of his own worth, but which are dependent on the participation of other people (Oatley \& Bolton, 1985, 377).

If a social role can no longer be fulfilled, a person might consider his or her disease as declining, or even severe. So, if health is perceived as threatening or declining, self-management strategies might be used to prevent or delay further disability. However, motivation to participate in self-management strategies comes from a sense of validation in social roles. Thus, how a person perceives his or her performance in a social role directly influences his or her attitude toward self-management programs. Most importantly, however, should be the attempt to change how people think about their arthritis and themselves and how their thoughts influence their behavior. 
From the data I collected, formal arthritis self-management programs [not simply individual strategies] are underutilized by people with the disease because: 1) course content is unknown, 2) program is 'unnecessary' until symptoms are severe (all assumed will be later in life), and 3) perceived target audience (for the elderly population). McDonald-Miszczak and Wister (2005) found that "participation in self-management is a reaction to health problems or deteriorating health such that the effect of age on self-management is probably an indirect result of changing health conditions as one ages" ( $p$ 838). Most of the participants felt as if they could 'cope' or 'deal' with daily symptoms through learned (or experienced), personal strategies.

Because environmental factors are believe to be directly linked to health outcomes (Shiloh, 2006), there are several external contributing factors as to why people with arthritis do not actively participant in self-management programs. Participants stated that self-management programs were not 'advertised' or 'promoted.' A participant (Female, 66) said: “I think - in theory, it's a great idea. Ijust don't see a lot of them offered... and if they are, I don't hear about it." Another participant (Male, 38) felt if he needed to practice self-management his rheumatologist would have advised him to do so.

In addition, this study found that people with arthritis have an incorrect understanding of arthritis self-management programs. Eight of the participants had not ever taken a self-management program because such programs were not perceived to have any individual benefits. A participant (Male, 38) said: "I am not sure how much it would help me" while another (Female, 42) said: "I don't think it would help. I don't know what I would learn that I don't already know."Yet 
another (Female, 68) said: "I don't think I need to take one. Not now." The content of arthritis self-management programs is unknown and should be effectively communicated to the population.

This study has several limitations in regards to the 'big picture' of arthritis. First, qualitative sampling is not purposed to generalize over a specific population. Instead, qualitative interviews are meant to give insight into a particular phenomena. In this case, arthritis and social roles are better understood from a patient's perspective. Thoughts on self-management strategies and the perception of such programs may be heard, but cannot be fully legitimatized due to the small sample.

Next, this study cannot suggest what future steps might be taken to improve the attendance to arthritis self-management programs. Instead, this study only aims at understanding why people with arthritis may not be attending such programs. Only opinions and perceptions were gathered here.

More public awareness and education about arthritis and other chronic disease might enable illness or disability to live among us. Arthritis selfmanagement programs are misconceived among people with arthritis. In addition, it might be said that arthritis and its symptoms are misconceived among people without the disease. While those with the disease understand the possible course of the disease, few choose to acknowledge those future threats now, in the present. This attitude or self-perception influences how people with arthritis care for, or manage their disease.

There is a gap in communication that exists between people with arthritis, health care professionals, and even outsiders - like family and friends. 
Unfortunately, few people with arthritis are able to find a common ground in which to express themselves and their thoughts and feelings on the disease because arthritis is ever-changing.

This study found that people with arthritis are not focused on healing or recovering, because that simply is not possible. Instead, people with arthritis are focused on maintaining, not to be confused with maintenance. Maintaining here means to stay in a social role, like parent, spouse, or employee. Participants want to maintain a social identity, even if 'crossing the line.' Maintaining is constantly changing (or, 'adjusting') with disease severity, age, and psychological well-being. Maintenance, on the other hand, is static. Because arthritis is unpredictable in all aspects, people with the disease are having to constantly adjust. Adjusting to pain, stiffness, side effects from new medications, changes in the body, deformities, limitations. Life for people with arthritis becomes adjustment.

Future research should examine a number of facets. First, research should examine specific social roles. Psychological well-being following diagnosis should also be studied, and perhaps at different levels of severity in the disease. It should be learned how people cope during a flare versus a time of ease. Also, how does a person with arthritis determine adjustment?

Next, future research should examine individual's experience with pain. Participants in this study all reported 'constant pain' due to arthritis. However, only when pain was severe did participants limit their lifestyles or valued activities. Thus, it must be understood the differing pain tolerances or pain levels for people with arthritis and how various levels determine a person's participation in activities, including social roles. 
In addition, all participants reported asking their rheumatologist for information on arthritis-related topics. It might be asked if a doctor recommended arthritis self-management program would be of consideration to people, especially if course content was known and specific to disease severity and social role. 


\section{Appendix I}

\section{INTERVIEW PARTICIPANT SURVEY}

Gender

Male Female

Age:

Marital Status

Married

Divorced

Single

Separated

Widowed

Roommate

Other

Number of years of education

Employment Status

Retired/Disabled

Full-time (over 30 hours per week)

Part-time (under 30 hours per week)

Unemployed

Yearly family income under $\$ 15,000$

$\$ 15,001-19,999$

$\$ 20,000-24,999$

$\$ 25,000-34,999$

$\$ 35,000-49,999$

$\$ 50,000-74,999$

$\$ 75,000+$

Ethnic Group

Check all that apply

White

Black

Asian

Pacific Islander

American Indian

Hispanic

Other/I don't know
What type of disease do you have?

Check all that apply

Don't know

Rheumatoid arthritis

Osteoarthritis

Fibromyalgia

Gout

Pseudogout

Psoriatic arthritis

Ankylosing Spondylitis

Polymyalgia Rheumatica

Sjogren's Syndrome

Lupus (SLE)

Reiter's Syndrome

Giant Cell and Temporal Arteritis Mixed Connective Tissue Disease

Necrotizing Vaculitis or

Wegner's Granulomatosis

Juvenile Rheumatoid Arthritis

Progressive Systemic Sclerosis or Scleroderma

Polymyositis or Dermatomyositis Other condition not mentioned

above

Approximately when were you diagnosed with rheumatic disease by a physician? (MM/YYYY) I

Are you being treated for any of the following chronic illnesses?

Check all that apply

Diabetes

High Blood Pressure

Emphysema

Osteoporosis

Thyroid Disease

Heart Failure

Coronary Artery Disease

Depression

Peptic Ulcer

Stroke

Asthma

High Cholesterol

Other 


\title{
Appendix II
}

\section{INTERVIEW GUIDE}

\author{
Ice Breakers
}

Tell me a little about yourself. (Employment? Family? Hobbies?)

\section{Disease Diagnosis}

How long have you had arthritis?

Do you see a rheumatologist on a regular basis?

Talk about the diagnosis. (How did you feel? What else was going on in your life? How did other people react? How did you react?)

Talk about your experience with arthritis. Remission? Medications? Limitations? Challenges?

(If the participant is married...) How did your spouse react to the diagnosis? Children?

\section{Social Roles}

What role does arthritis fill in your life?

What role in society do you think you play?

How do you think you fit into society? into your social group?

What daily roles do you fill within your own life, but also in others? (For example, are you filling the roles of wife, mother, daughter, sister, friend, employee, etc.?)

(If the participant is married...) How does your spouse react to you when your arthritis "flares" or you face limitations?

How has arthritis changed (or shaped) your relationship?

How do you feel in relation to your spouse? Do you feel as if you and your disease are understood?

(If the participant has children...) How do your children feel about your disease? How did you explain the diagnosis?

Do you ever experience limitations when it comes to caring for your children? How do you think your children view you?

How does your arthritis affect other people in your life? 


\section{Self-Management}

Tell me about a time that you thought arthritis was controlling your life.

Have you ever felt challenged by arthritis symptoms? (For example, you are forced to sit and rest while shopping at the mall with friends.)

How do these challenges make you feel about yourself? about your arthritis?

Do you practice any self-management strategies for managing your arthritis? (If so, what strategies?)

Have you ever participated in an arthritis self-management program?

(If yes...) What program did your participate in? How did you hear about the program? Do you continue to benefit from the program? What aspects of the program did you find most useful? least useful?

Do you have anything to add about your experiences with an arthritis selfmanagement program?

(If no...) Why have you not participated in an arthritis self-management program? Have you heard of arthritis self-management program? Do you think you would benefit from an arthritis self-management program?

Do you have anything to add about your perception of arthritis self-management programs?

\section{Health Communication}

Where do you look for health information? as related to your disease?

Do you enjoy reading or learning about arthritis?

Do you have Internet access?

Do you attend support group meetings? (If no...) Have you ever considered attending a meeting?

Who do you talk to about your disease?

Have others ever suggested you seek information about your disease? Or other topics related to arthritis (i.e., nutrition, exercise, medication)?

Have you asked your physician for information?

What format do you prefer health information (i.e., internet, book, class)? 


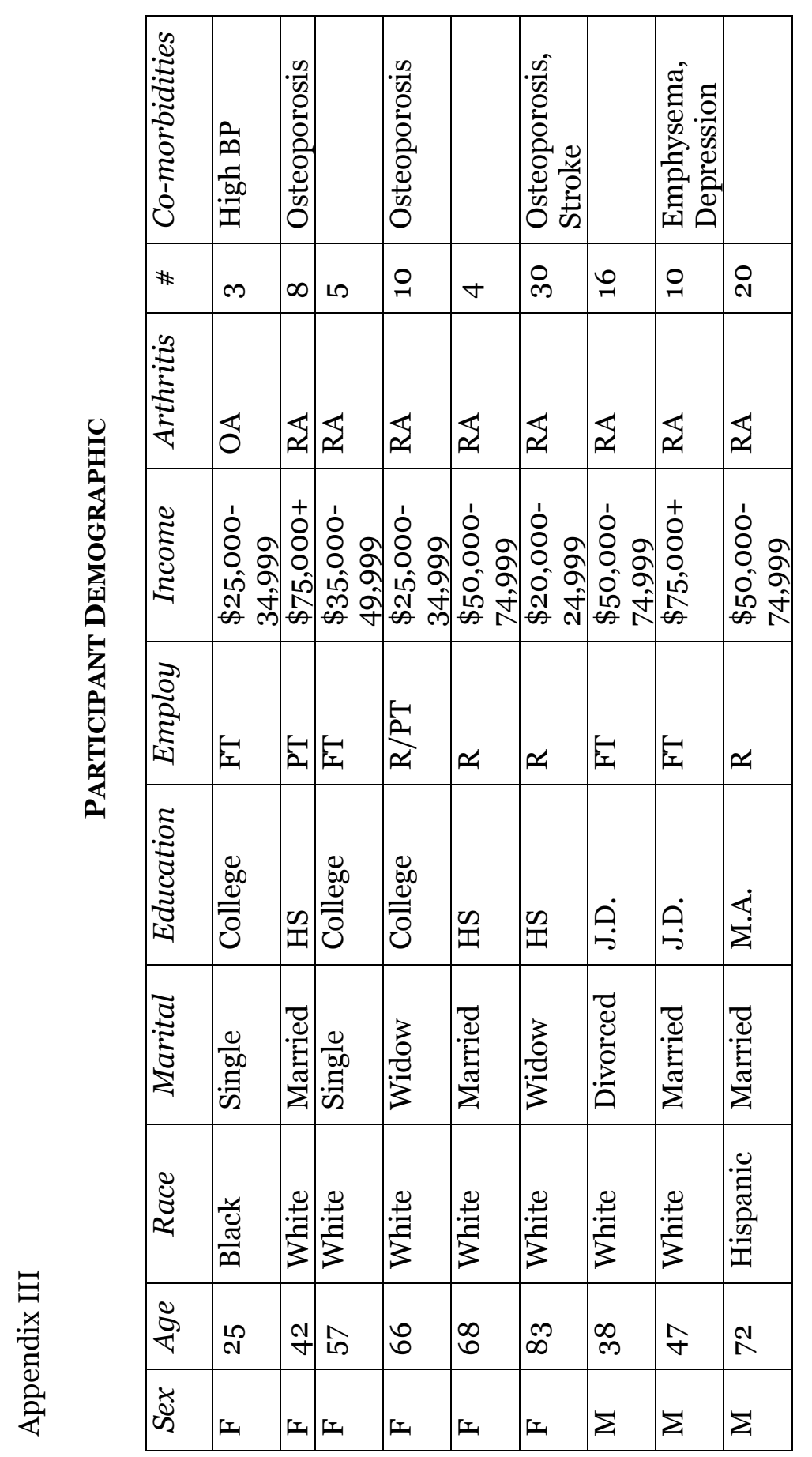




\section{BIBLIOGRAPHY}

Abraido-Lanza, Ana. (1997). Latinas with Arthritis: Effects of Illness, Role Identity, and Competence on Psychological Well-Being. American Journal of Community Psychology, 25(5), 601-627.

Abraido-Lanza, Ana \& Revenson, Tracey. (2006). Illness Intrusion and Psychological Adjustment to Rheumatic Diseases: A Social Identity Framework. Arthritis \& Rheumatism, 55(2), 224-232.

Agar, M. (1980). The Professional Stranger: An Informal Introduction to Ethnography. Academic Press: London.

Ajzen, Icek. (1991). The theory of planned behavior. Organizational Behavior and Human Decision Process, 50 (2), 179-211.

Bandura, Albert. (2004). Health Promotion by Social Cognitive Means. Health Education \& Behavior, 31(2), 143-164.

Beiseker, Analee E. \& Beiseker, Thomas D. (1993). Using Metaphors to Characterize Doctor-Patient Relationships: Paternalism Versus Consumerism. Health Communication, 5, 1, 41-58.

Bowen, D.J., Helmes, A. Lease, E. (2001). Predicting compliance: how are we doing? In Burke, L.E. Ockene, I.S. (Eds.), Compliance in Healthcare and Research (pp 2541). Armonk, NY: Futura.

Brady, Teresa, Kruger, Judy, Helmick, Charles G., Callahan, Leigh F., Boutaugh, Michele L.. (2003). Intervention Programs for Arthritis and Other Rheumatic Diseases. Health Education and Behavior, 30(1), 44-63.

Burgess, R. (ed.) (1982). Field Research: A Source Book and Field Manual. Unwin Hyman: London.

Burks, Kathryn J., Smarr, Karen, \& Laffey, James. (2006). Developing a Web-Based Chronic Illness Management Program. International Nursing Library Conference.

Carr, A.J.. (1996). A Patient-Centered Approach to Evaluation and Treatment in Rheumatoid Arthritis: The Development of a Clinical Tool to Measure PatientPerceived Handicap. British Journal of Rheumatology, 35, 921-932.

Centers for Disease Control and Prevention, Healthy People 201O, 2001.

Centers for Disease Control and Prevention, National Center for Health Statistics, National Health Interview Survey, 2003. 
Centers for Disease Control and Prevention. (2005). The Journal of the American Medical Association, 294(7).

Charmaz, Kathy. (1983). Loss of self: a fundamental form of suffering in the chronically ill. Sociology of Health and Illness, 5(2), 169-195.

Christians, Clifford G. \& Carey, James W. (1989). The logic and aims of qualitative research. In G.H.I. Stempel \& BH Wesley (eds.) Research Methods in Mass Communication, 354-374. Englewood Cliffs, New Jersey: Prentice Hall.

Denzin, Norman K. \& Lincoln, Yvonne S. (eds.). Collecting and Interpreting Qualitative Materials. $2^{\text {nd }}$ ed. Thousand Oaks: Sage Publications, 2003.

Devins, G.M. (1989). Enhancing personal control and minimizing illness intrusiveness, maximizing rehabilitation in chronic renal disease. In N.G. Kutner, D.D. Cardenas and J.D. Bower (Eds.), Maximizing rehabilitation in chronic renal disease (pp. 109-136). New York: PMA.

DiMatteo, M. Robin, Haskard, Kelly B., Williams, Summer L.. (2007). Health Beliefs, Disease Severity, and Patient Adherence. Medical Care, 45(6), 521-528.

Draper, AK. (2004). The principles and applications of qualitative research. Proceedings of the Nutrition Society, 63, 641-646.

Ethier, Kathleen A. \& Deaux, Kay. (1994). Negotiating Social Identity when Contexts Change: Maintaining Identification and Responding to Threat. Journal of Personality and Social Psychology, 67(2), 243-251.

Gallant, Mary P.. (2003). The Influence of Social Support on Chronic Illness SelfManagement: A Review and Directions for Research. Health Education \& Behavior, 30(2), 170-195.

Gerhardt, U. (1990). Qualitative research on chronic illness: the issue and the story. Social Science and Medicine, 30(11), 1149-1159.

Glasgow, Russell E., Strycker, Lisa A., Toobert, Deborah J., Eakin, Elizabeth. (2000). A Social-Ecologic Approach to Assessing Support for Disease Self-Management: The Chronic Illness Resources Survey. Journal of Behavioral Medicine, 23(6), 559-582.

Gortner, S. (1990). Nursing values and science towards a science philosophy. Image Journal of Nursing Scholarship, 22(2), 101-105. 
Green, L.W.. (1999). Health Education's Contributions to Public Health in the Twentieth Century: A Glimpse Through Health Promotion's Rear-View Mirror. Annual Review of Public Health, 20, 67-88.

Hammond, A.. (1998). The use of self-management strategies by people with rheumatoid arthritis. Clinical Rehabilitation, 12, 81-87.

Janz, Nancy K., Becker, Marshall H.. (1984). “The Health Belief Model: A Decade Later.” Health Education and Behavior, 11 (1), 1-47.

Jensen, Klaus B. \& Jankowski, Nicholas W. (eds.) A Handbook of Qualitative Materials. $2^{\text {nd }}$ ed. Thousand Oaks: Sage, 2003.

Jensen, Mark P., Nielson, Warren R., Kerns, Robert D.. (2003). Toward the Development of a Motivational Model of Pain Self-Management. The Journal of Pain, 4(9), 477-492.

Karp, David A. (1980). Observing Behavior in Public Places: Problems and Strategies. In William B. Shaffir, Robert A. Stebbins, and Allen Turowetz (eds.) Fieldwork Experience: Qualitative Approaches to Social Research, 82-97. New York: St. Martin's Press.

Keefe, Francis J.; Lefebvre, John C.; Kerns, Robert D.; Rosenberg, Roberta; Beaupre, Pat; Prochaska, Judith; Prochaska, James O. and Caldwell, David S. (2000). Understanding the adoption of arthritis self-management: stages of change profiles among arthritis patients. Pain, 87, 303-313.

Keysor, Julie J., DeVellis, Brenda M., DeFriese, Gordon H., DeVellis, Robert F., Jordan, Joanne M., Konrad, Thomas R., Mutran, Elizabeth J., Callahan, Leigh F.. (2003). Critical Review of Arthritis Self-Management Strategy Use. Arthritis \& Rheumatism, 49(5), 724-731.

Kruger, Judy M.S., Helmick, Charles G., Callahan, Leigh F., Haddix, Anne C.. (1998). Cost-effectiveness of the Arthritis Self-Help Course. Archives of Internal Medicine, 158, 1245-1249.

Lofland, John \& Lofland, Lyn H. (1984). Logging Data. In Analyzing Social Settings: A Guide to Qualitative Observation and Analysis, 66-99.

Lorig, Kate, Sobel, David, Stewart, Anita, Brown, Byron William Jr., Bandura, Albert, Ritter, Phillip, Gonzalez, Virginia, Laurent, Diana, Holman, Halsted. (1999). Evidence Suggesting That a Chronic Disease Self-Management Program Can Improve Health Status While Reducing Hospitalization: A Randomized Trial. Medical Care, 37(1), 5-14. 
Lorig, K., Ritter, P., Stewart, A., Sobel, D., et. al. (2001). “Chronic Disease SelfManagement Program: 2-Year Health Status and Health Care Utilization Outcomes.” Medical Care, 39 (11), 1217-1223.

Lorig, Kate R., Ritter, Philip L., Laurent, Diana D., Fries, James F.. (2004). Long-Term Randomized Controlled Trials of Tailored-Print and Small-Group Arthritis SelfManagement Interventions. Medical Care, 42(4), 346-354.

Lorig, Kate, Ritter, Philip L., Plant, Kathryn. (2005). A Disease-Specific Self-Help Program Compared With a Generalized Chronic Disease Self-Help Program for Arthritis Patients. Arthritis \& Rheumatism, 53(6), 950-7.

Matthews, C.K., \& Harrington, N.G. (2000). Invisible disability. In D.O. Braithwaithe \& T.L. Thompson (Eds.), Handbook of communication and people with disabilities: Research and application (p 405-421). Mahwah, NJ: Lawrence Erlbaum Associates, Inc.

McDonald-Miszczak, Leslie, Wister, Andrew V.. (2005). Predicting Self-Care Behaviors Among Older Adults Coping With Arthritis. Journal of Aging and Health, 17(6), 836-857.

Morse, J. (ed.) (1989). Qualitative Nursing Research: A Contemporary Dialogue. Sage: Newbury Park, California.

Munhall, P. (1981). Nursing philosophy and nursing research in apposition or opposition. Nursing Research, 31(3), 176-181.

Newman, Stanton, Steed, Liz, Mulligan, Kathleen. (2004). Self-management interventions for chronic illness. Lancet, 364, 1523-37.

Oatley, Keith \& Bolton, Winifred. (1985). A Social-Cognitive Theory of Depression in Reaction to Life Events. Psychological Review, 92(3), 372-388.

Oiler, C. (1982). The phenomenological approach in nursing research. Nursing Research, 31(3), 178-181.

Parrott, Roxanne. (2004). Emphasizing “communication” in Health Communication. Journal of Communication, 54, 751-787.

Revenson, Tracey \& Felton, Barbara. (1989). Disability and Coping as Predictors of Psychological Adjustment to Rheumatoid Arthritis. Journal of Counseling and Clinical Psychology, 57(3), 344-348.

Shiloh, Shoshana. (2006). Illness Representations, Self-Regulation, and Genetic Counseling: A Theoretical Review. Journal of Genetic Counseling, 15(5), 325-337. 
Strating, Mathilde M.H., Wijbrandt, van Schuur H., Suurmeijer, Theo P.B.M.. (2006). Contribution of Partner Support in Self-Management of Rheumatoid Arthritis Patients. An Application of the Theory of Planned Behavior. Journal of Behavioral Medicine, 29(1), 51-60.

Theis, Kristina, Helmick, Charles, and Hootman, Jennifer. (2007). Arthritis Burden and Impact Are Greater among U.S. Women than Men: Intervention Opportunities. Journal of Women's Health, 16(4), 441-453.

Thoits, P.A. (1991). On merging identity theory and stress research. Social Psychology Quarterly, 54, 101-112.

Velicer, W.F.; Hughes, S.L.; Fava, J.L.; Prochaska, J.O.; DiClemente, C.C. (1995). An empirical typology of subjects within stage of change. Addictive Behaviors, 20, 299-320.

Watson, J. (1985). Nursing: Human Science and Human Care. Appleton Century Crofts: Norwalk, Connecticut.

Whyte, William Fotte. (1982). Interviewing in Field Research. In Robert G. Burgess (ed.) Field Research: Sourcebook and Field Manual, 111-122. London: George Allen \& Unwin. 